University of Nebraska - Lincoln

DigitalCommons@University of Nebraska - Lincoln

2012

\title{
On Modeling Weak Sinks in MODPATH
}

Daniel Abrams

Indiana University, dbabrams@indiana.edu

H. Haitjema

Indiana University, haitjema@indiana.edu

L. Kauffman

U.S. Geological Survey, ljkauff@usgs.com

Follow this and additional works at: https://digitalcommons.unl.edu/usgsstaffpub

Abrams, Daniel; Haitjema, H.; and Kauffman, L., "On Modeling Weak Sinks in MODPATH" (2012). USGS Staff-- Published Research. 589.

https://digitalcommons.unl.edu/usgsstaffpub/589

This Article is brought to you for free and open access by the US Geological Survey at DigitalCommons@University of Nebraska - Lincoln. It has been accepted for inclusion in USGS Staff -- Published Research by an authorized administrator of DigitalCommons@University of Nebraska - Lincoln. 


\title{
On Modeling Weak Sinks in MODPATH
}

\author{
by Daniel Abrams ${ }^{1}$, H. Haitjema² ${ }^{2}$ and L. Kauffman ${ }^{3}$
}

\begin{abstract}
Regional groundwater flow systems often contain both strong sinks and weak sinks. A strong sink extracts water from the entire aquifer depth, while a weak sink lets some water pass underneath or over the actual sink. The numerical groundwater flow model MODFLOW may allow a sink cell to act as a strong or weak sink, hence extracting all water that enters the cell or allowing some of that water to pass. A physical strong sink can be modeled by either a strong sink cell or a weak sink cell, with the latter generally occurring in low-resolution models. Likewise, a physical weak sink may also be represented by either type of sink cell. The representation of weak sinks in the particle tracing code MODPATH is more equivocal than in MODFLOW. With the appropriate parameterization of MODPATH, particle traces and their associated travel times to weak sink streams can be modeled with adequate accuracy, even in single layer models. Weak sink well cells, on the other hand, require special measures as proposed in the literature to generate correct particle traces and individual travel times and hence capture zones. We found that the transit time distributions for well water generally do not require special measures provided aquifer properties are locally homogeneous and the well draws water from the entire aquifer depth, an important observation for determining the response of a well to non-point contaminant inputs.
\end{abstract}

\section{Introduction}

MODPATH (Pollock 1994) is a particle tracing code that uses the cell-by-cell flows and potentiometric heads generated by the numerical groundwater flow model MODFLOW (McDonald and Harbaugh, 1988). The (regional) flow systems modeled by MODFLOWMODPATH typically contain both strong sinks and weak sinks. A physical strong sink extracts water from the entire aquifer depth, while a physical weak sink lets some water pass underneath the sink in the case of a surface water feature or over/underneath the sink in the case of a pumping well. Similarly, a MODFLOW model may contain cells that act as strong sinks or weak sinks, hence extract

${ }^{1}$ Corresponding author: School of Public and Environmental Affairs, Indiana University SPEA 412, Bloomington, IN 47405; (812) 339-5934; fax: (812) 855-7802; dbabrams@indiana.edu

${ }^{2}$ School of Public and Environmental Affairs, Indiana University SPEA 412, Bloomington, IN 47405; (812) 339-2840; haitjema@indiana.edu

${ }^{3}$ U.S. Geological Survey, New Jersey Water Science Center, 810 Bear Tavern Rd. Suite 206, West Trenton, NJ; (406) 754-3332; ljkauff@usgs.com

Received December 2011, accepted August 2012.

(C) 2012, The Author(s)

Ground Water (C) 2012, National Ground Water Association.

doi: 10.1111/j.1745-6584.2012.00995.x all water that enters the cell or allow some of it to pass, respectively.

Either a strong sink cell or a weak sink cell may represent an actual physical strong sink. An example of the latter is a strong sink well whose capture zone does not fully cover the well cell (Spitz et al. 2001). Likewise, either type of sink cell may also represent a physical weak sink. The representation of physical strong and weak sink features in MODFLOW is generally straightforward and will lead to the appropriate sink strengths, at least in so far as allowed by the model resolution. The representation of physical weak sinks in MODPATH, however, is not straightforward and often leads to errors in particle tracing, both in terms of particle paths and particle travel times. In this study, the term travel time refers to the time a particle travels from some point to another in the aquifer, while transit time refers to the travel time of a particle from recharge to discharge and groundwater age refers to the travel time of a particle from recharge to its current location.

Many modeling reports from the U.S. Geological Survey (USGS) discuss the impact of MODPATH's weak sink settings on the contributing area of recharge (catchment) for high capacity pumping wells (Barlow 1997; Kauffman et al. 2001; Kelly 2004; Cherry 2006; Paschke et al. 2007). Such wells can always be represented by strong 
sink cells by using a sufficiently fine modeling grid, either globally or locally, in MODFLOW. Spitz et al. (2001) proposed an ad hoc nested rediscretization of only weak sink cells in a MODFLOW-MODPATH model. In this method, particles are back traced from the rediscretized well cell until they reach a boundary of the original weak sink cell, at which point they are back traced in the original model to their point of recharge. Paschke et al. (2007) also discretize the weak sink cell, but forward trace particles in the regional model until they reach the weak sink cell where they are stopped. The particles are then forward traced in a rediscretized model until they either terminate at the (small) well cell or reach a boundary of the original cell and are transferred back to the original model to continue forward tracing. A drawback to the methods proposed by Spitz and Paschke is the additional time required to construct and run the rediscretized models. Alternatively, Zheng (1994) proposed an analytic approximation of flow inside the weak sink cell using the expression for a well in a uniform flow field (Bear 1972), which then allows for gridless particle tracing inside the cell. Visser et al. (2009) seem to be the only authors addressing the modeling of weak sink streams in MODPATH. Their proposed Splitpath method exploited the presence of weak sink cells in a coarse regional model to improve somewhat on the transit time distribution in the watershed, but does not correctly represent the vertical stratification of transit times in an aquifer.

In this study, we first discuss the MODPATH settings that impact particle tracing to and through weak sink cells. We next review the impact of physical weak sinks representing surface water on individual groundwater pathlines and associated groundwater travel times as well as on transit time distributions. Finally, we investigate the impact of weak sink cells representing high capacity pumping wells that act as physical strong sinks (and to a lesser extent low capacity wells that act as physical weak sinks). We offer suggestions for optimal MODPATH model setups when modeling both surface water and wells without intervention in the code.

\section{MODPATH Handling of Weak Sinks}

Many regional flow systems contain physical weak sinks and most regional MODFLOW models will contain weak sink cells (Pollock 1994). Weak sink cells in MODFLOW and MODPATH are defined by their relative strength $S$ :

$$
S=\frac{Q_{\text {sink }}}{Q_{\text {in }}}
$$

where $Q_{\text {sink }}\left[\mathrm{L}^{3} / \mathrm{T}\right]$ is the discharge rate to the sink and $Q_{\text {in }}\left[\mathrm{L}^{3} / \mathrm{T}\right]$ is the discharge rate to the corresponding sink cell. Thus, for a strong sink cell $S=1$ and for a weak sink cell $S<1$. MODPATH offers the user three options for particles that arrive at a weak sink cell: always STOP, always PASS, or a conditional STOP. The conditional STOP allows a particle to pass through the cell if $S$ is below some specified value, otherwise the particle is stopped. For instance, if the conditional STOP parameter is set at 0.5 , then a particle will pass all sink cells with $S<0.5$ and stop at all sink cells with $S \geq 0.5$. These MODPATH settings are global; they apply to all sink cells in the model.

Along with sink strengths, MODPATH receives the cell-by-cell flows generated by MODFLOW and linearly interpolates velocities in the $x$-, $y$-, and $z$-directions across a cell. The interpolated velocities are used to generate particle pathlines and particle travel times. While this procedure works well in the presence of strong sink cells, Pollock (1994) states that "there is no way to know whether a specific particle should discharge to the sink or pass through the [weak sink] cell." This is an often quoted statement (Spitz et al. 2001; Cherry 2006; Paschke et al. 2007; Visser et al. 2009), but is only true if the sink is envisioned as uniformly distributed throughout the sink cell. This is the default interpretation used in MODPATH.

In MODPATH, users may also specify where water will be discharged in a sink cell by use of the IFACE parameter (Pollock 1994). Unlike the STOP option, which is a global setting, IFACE can be set for every individual sink cell. The default setting for all types of sink cells is IFACE $=0$. When IFACE $=0$ and MODPATH is set to stop particles arriving at a weak sink cell, particles will be stopped as soon as they reach any of the cell's faces. Setting IFACE $=6$ will stop particles at the top face of the cell provided it is adjacent to an inactive cell or the model boundary. For that case, therefore, the actual sink occurs at the top of the cell (uniformly distributed over that cell surface). The same is true for the other five cells faces by setting IFACE $=1-5$. The actual MODPATH settings that should be applied are dependent on the type of sink (surface water or pumping well) being investigated, as we will demonstrate.

\section{Modeling Surface Water Weak Sinks}

In an aquifer with only physical strong sinks, all water that falls between a water divide and a sink is expected to enter that sink (Figure 1a). As a result, the groundwater age is expected to increase monotonously with depth everywhere in the aquifer, at least in the simple setting shown in Figure 1. A physical strong sink that draws water from the entire depth of the aquifer will thus draw water from a theoretical age range of zero to infinity (Haitjema 1995). We define the age distribution or transit time distribution of groundwater entering a sink by use of the cumulative relative frequency distribution (CRFD) of transit times (Figure 1b). For the whole watershed of a stream, the CRFD indicates the fraction of the base flow at the watershed outlet that has a groundwater transit time of $T$ days or less (Maloszewski and Zuber 1982; Haitjema 1995; McGuire and McDonnell 2005). The CRFD curve for the simple 1D system in Figure 1 is a negative exponential function (Gelhar and Wilson 1974), which also applies to more complex 2D flow systems (Haitjema 1995). These transit time distributions are of 

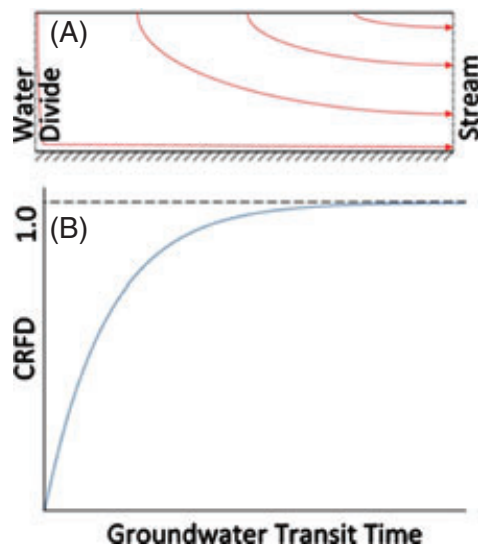

Figure 1. (a) Cross-sectional view of particle traces in a 1D flow system. (b) Associated CRFD of groundwater transit times.

interest in the context of non-point source contaminants, for example, to obtain nitrate response functions in wells or streams in a watershed (Lerner and Papatolios 1993; Haitjema 1995; Rodhe et al. 1996; Kauffman et al. 2001; McGuire and McDonnell 2005; McDonnell et al. 2010).

Weak sinks do not draw water from the entire aquifer depth, and, therefore, do not receive water with transit times ranging from zero to infinity. In fact, a weak sink surface water body (e.g., stream, drain, and lake) will discharge groundwater flowing in the upper portion of the aquifer with smaller transit times and allow deeper water with longer transit times to pass (see Figure 2). Consequently, the CRFD for a weak sink stream, which receives only younger water, and nearby strong sink streams, which receive the older water bypassed by the weak sink, will typically not have the negative exponential distribution shown in Figure 1b.

Whether the physical weak sink in Figure 2 is modeled with MODFLOW in a thin upper layer as a strong sink cell (see Figure 3a), over the entire aquifer thickness as a weak sink cell (see Figure 3b), or any other vertical discretization, discharges to the sink will be calculated correctly. In order to correctly model particle traces and particle transit times, however, it is necessary that MODPATH stops the correct particles and passes the correct

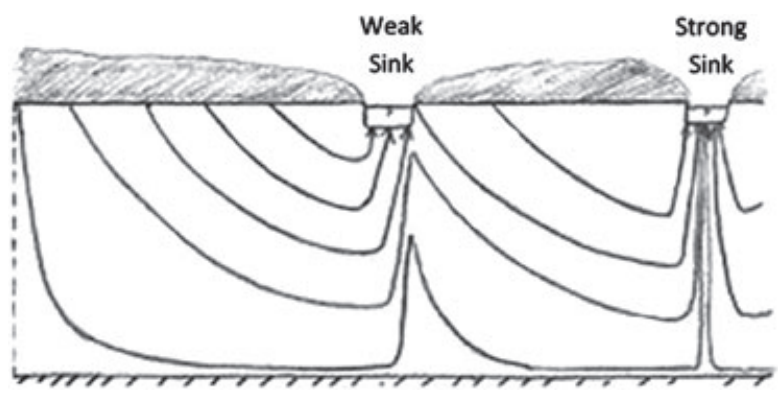

Figure 2. Conceptual model of a physical weak sink, which draws water from the upper portion of the aquifer only, and a physical strong sink, which draws water from the entire aquifer depth.
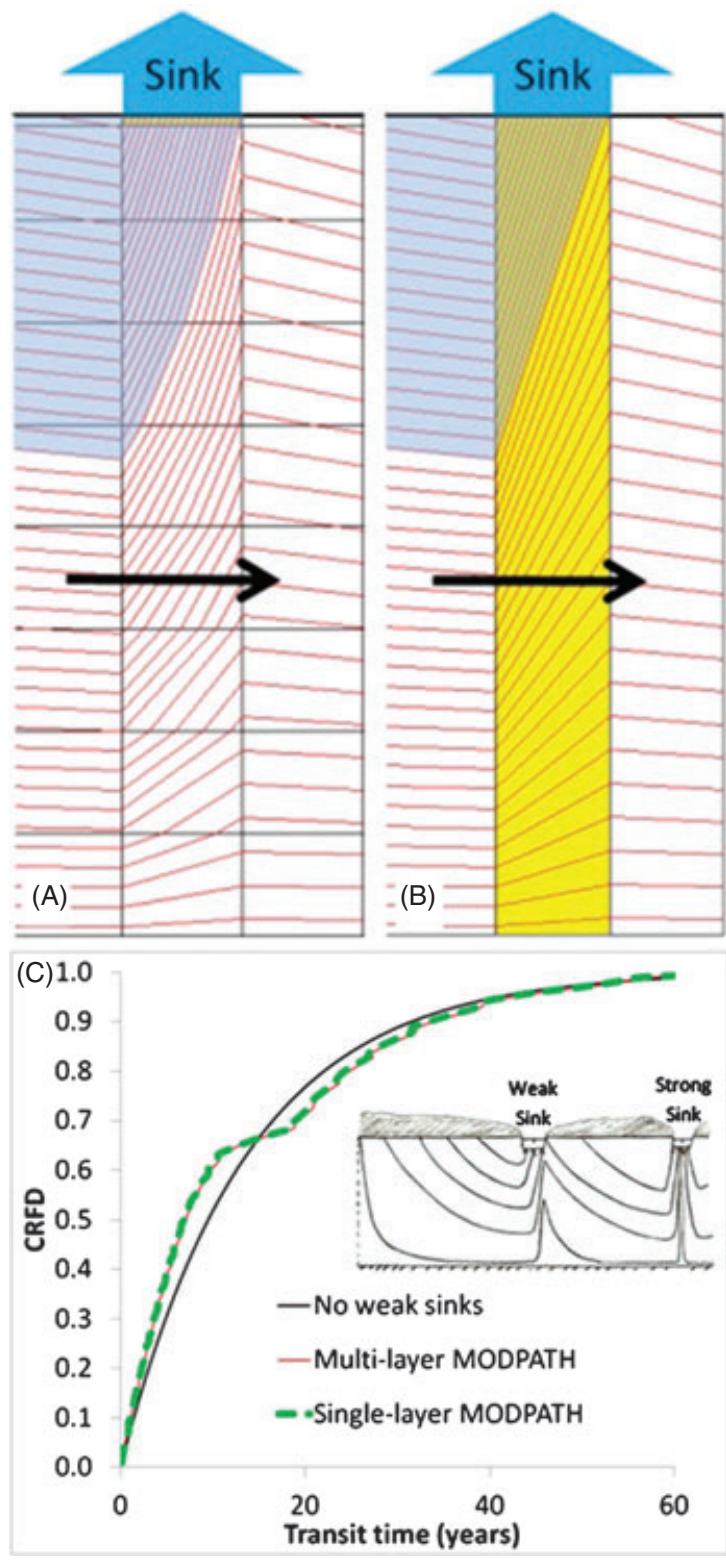

Figure 3. Two cross-sectional views of pathlines traced to a weak sink in the conceptual model in Figure 2 for (a) a multilayered model and (b) a single-layer model. The sink cells are yellow, and the black arrows indicate the direction of flow. In both models, IFACE $=6$ and pathlines in the blue shaded area enter the sink cell. (c) The CRFD of groundwater transit times are nearly identical for both MODPATH models but deviate from the distribution where weak sinks are not present.

particles. For weak sinks, this means that the shallow particles with relatively short transit times must be stopped and deeper particles passed. This can be accomplished, regardless of MODFLOW resolution, if MODPATH settings are set to "always STOP" particles at weak sinks and IFACE $=6$.

To test the performance of MODPATH in a simple 1D setting with weak sinks, two MODFLOW-MODPATH models representing the conceptual model in Figure 2 were built: (1) a multilayered reference model in which a weak sink stream is represented by strong sink cells in 
the thin (1-foot thick) upper layer, and (2) a single layer model in which a weak sink stream is necessarily represented by weak sink cells. The two models have identical properties, including a very high vertical hydraulic conductivity of $k_{\mathrm{h}}=100,000 \mathrm{~m} / \mathrm{d}$ to effectively remove resistance to vertical flow and ensure that both models behaved as Dupuit-Forchheimer models (Kirkham 1967). MODPATH was set to "always STOP" and IFACE = 6 for both models. The multilayered model allows for more geometrically accurate pathlines traced to the weak sink (Figure 3a) compared to the single layer model (Figure 3b). The transit times associated with the pathlines, however, were similar, with the greatest difference being $0.5 \%$ for the shortest transit time; $90 \%$ of the particles had a percent difference of less than $0.01 \%$. As a result, the corresponding CRFDs for the watershed are indistinguishable on the scale of Figure 3c (the red solid and green dashed lines overlap). Note that both MODPATH CRFDs deviate from the negative exponential curve (solid black line), as expected.

It is noted that the approach to modeling CRFDs in models with weak sink streams offered by Visser et al. (2009) does not discriminate between the pathlines that are stopped at a weak sink cell. In their Splitpath method, all particles arriving at a weak sink cell are split into two particles. One of the two particles is stopped at the weak sink and given a weight $S$ as defined by Equation 1 . The particle that passes the weak sink is given a weight $1-S$. While these weights represent the correct volumes of water associated with particles stopped and passed at weak sinks, these particles do not represent the correct range of transit times. In fact, in a single layer model such as Figure 3b, the water entering the weak sink using Splitpath represents all transit times between zero and infinity as does the water that passes the weak sink, which is incorrect. As illustrated in Figure 2, the actual weak sink receives the shorter pathlines with younger water, while the longer pathlines with older water are passing through. It is noted that Visser et al. (2009) could not use IFACE $=6$ in their study of the Kemper area in the Netherlands because their model drain cells were in the second layer of their MODFLOW model, hence not on a boundary edge. Despite the fact that Splitpath does not generate the correct transit times for individual particle traces, it did offer an improvement to the CRFD of the area because their model had a coarse horizontal resolution. Under these circumstances, MODPATH stops too many particles with nearly zero transit times, while Splitpath allowed a portion of all of those particles to pass and accrue some transit times. In this manner, Splitpath reduced the bias of short transit times due to weak sink cells. We also considered weak sinks that occur when groundwater flows underneath a stream for a distance before being discharged downgradient, but found that it caused little impact to the negative exponential shape of the CRFD and in addition could be treated the same as the weak sinks already discussed in this study. Further details are available in the supporting information.

\section{Modeling Weak Sink Well Cells}

High capacity wells, whether partially penetrating or not, tend to draw water from the entire aquifer thickness and hence are physical strong sinks. Barlow (1997) demonstrated that this was typically true for wells with pumping rates greater than $1 \mathrm{Mgal} / \mathrm{d}\left(3785 \mathrm{~m}^{3} / \mathrm{d}\right)$, though in sand and gravel aquifers with relatively isotropic properties, wells with much smaller pumping rates could still draw from the entire aquifer thickness. For these high capacity strong sink wells, "always STOP" and IFACE = 0 should be selected in MODPATH and the well should be placed in the layers over which it is screened in MODFLOW. Given sufficient refinement, these strong sink wells will always be represented by strong sink cells since all of the water that enters the sink cell will discharge to the well (Figure 4a). However, in a coarse model, the capture zone of the well may fall within the well's sink cell, hence more water reaches the sink cell than will discharge to the well creating a weak sink cell (Figure 4b). Even in this latter case, IFACE $=0$ and "STOP" settings will still introduce tracing errors, stopping too many particles at the sink cell, and generating incorrect transit times. The only way to improve on these errors is either by using a rediscretization technique (Spitz 2001; Paschke et al. 2007) or an analytical solution (Zheng 1994). However, the CRFD for high capacity wells appears robust to coarse model grids.

To test our MODPATH setup for weak sink cells which represent physical strong sink wells, we compared two models for a semi-confined homogeneous aquifer with a thickness of $10 \mathrm{~m}$. The first model has a cell resolution of $10 \times 10 \mathrm{~m}$ and the second has a cell resolution of $110 \times 110 \mathrm{~m}$. The left-hand boundary of each model was assigned a constant head of $11 \mathrm{~m}$ and the right-hand boundary assigned a constant head of $10 \mathrm{~m}$ to create a uniform flow field. A single well was placed in the center of each model as shown in Figure 4. In Figure 4a the well is modeled by a strong sink cell and in Figure $4 \mathrm{~b}$ the well is modeled by a weak sink cell. MODPATH is set to "always STOP" and IFACE $=0$. In both cases, MODFLOW discharges the same amount of water per cell $\left(1500 \mathrm{~m}^{3} / \mathrm{d}\right)$. However, the weak sink cell receives much more water through its faces and thus MODPATH stops too many pathlines (Figure 4b), resulting in an overestimation of the capture zone for this well and the possible underestimation of the capture zones for downgradient wells.

While the capture zone for the weak sink cell in Figure $4 \mathrm{~b}$ is in error, its CRFD is virtually identical to that of the strong sink cell in Figure 4a; see the red solid and green dashed curves in Figure 5. The reason for the CRFDs are the same is that while MODPATH stops too many pathlines, it stops water from all depths. Consequently, MODPATH removes particles with all transit times ranging from zero to infinity. Since the CRFD is a relative frequency distribution, hence relative to the discharge (any discharge) of the well, the fact that the weak sink well cell stops too many particles is of no consequence. Note that in this example, the age distribution with depth is the same everywhere, which would generally be 


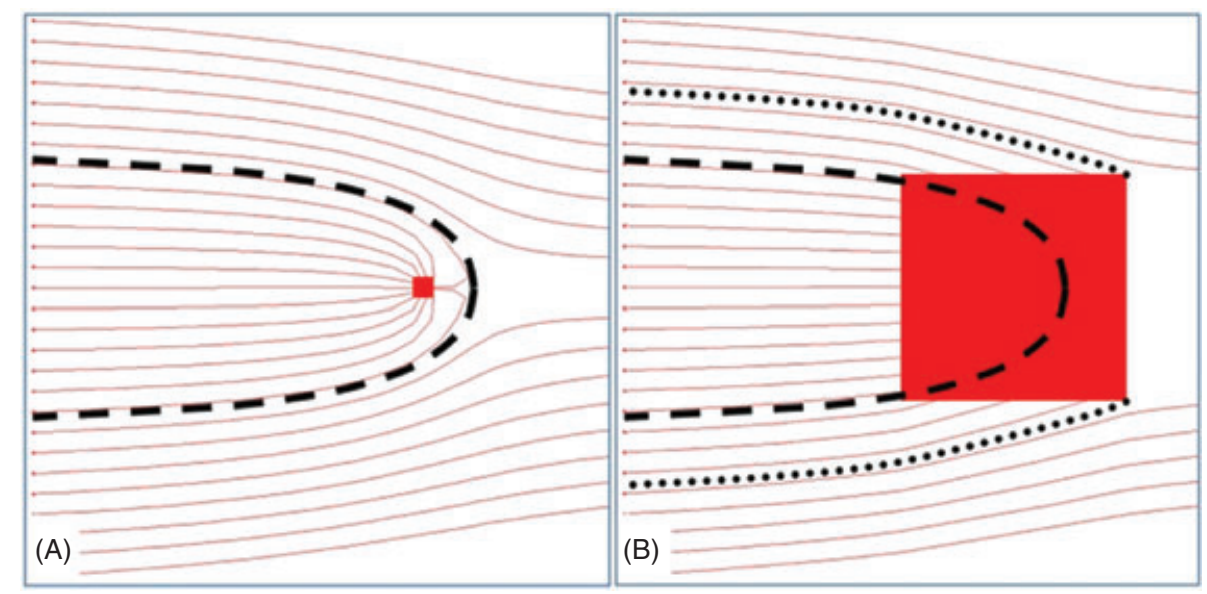

Figure 4. Plan view modeling results of a pumping well in MFMP when (a) the well cell falls entirely within the capture zone of the well and is thus a strong sink and (b) the well cell falls partially outside of the actual capture zone and is thus a weak sink.

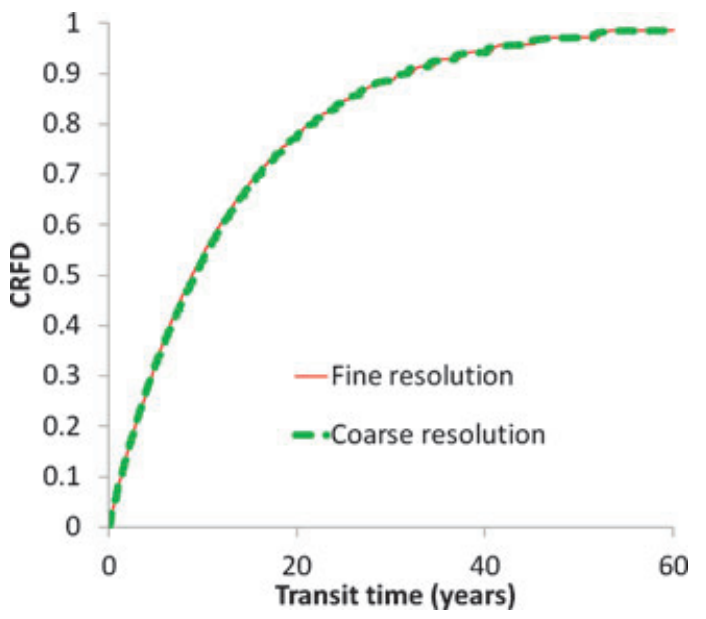

Figure 5. CRFD of groundwater transit times are the same for a high-resolution model where the well cell is a strong sink and a low-resolution model where the well cell is a weak sink (see Figure 4).

the case when recharge, saturated thickness, and porosity are locally constant. In practice, this would also be true if variations were small or random over a large regional area (Luther and Haitjema 1998). For cases where the age distribution with depth just outside of the actual capture zone is distinctly different from inside, model refinement would be necessary to generate the correct CRFD.

We further tested the sensitivity of the CRFD of wells in coarse models and found that the CRFD remained robust for high capacity pumping wells that act as strong sinks. Further details are available in the Supporting Information. For small capacity wells that act as physical weak sinks, where the CRFD appears to be more sensitive to discretization, it is common modeling practice to instruct MODPATH to stop at a specified strength between 0 and 1 (Barlow 1997; Cherry 2006; Paschke et al. 2007; Visser et al. 2009). The selection of the specified strength is model dependent and often arbitrary, hence model refinement may still be necessary to generate both correct capture zones and transit time distributions for these small capacity wells.

\section{Concluding Remarks}

The default MODPATH setting for the IFACE parameter is IFACE $=0$, which is appropriate for high capacity weak sink well cells, but generally not for weak sink stream cells (or any other sink cell that happens to fall on a model boundary). We found that the optimal MODPATH settings for weak sink surface water, such as streams, are the "always STOP" option in combination with IFACE $=6$. With these settings, the weak sink stream will stop the shallower pathlines with relatively short transit times and pass the deeper and older water, as happens in reality. This is true even for single layer models. To make the IFACE $=6$ setting work correctly, the top face of the weak sink cell should be at the stream bottom elevation and be on a model boundary (either the top of the model or adjacent to an inactive cell).

For internally distributed sinks such as well sink cells, IFACE should be set to zero. In regional models with rather large cells, well sink cells will likely be weak sinks because they extend outside of the well's capture zone. Hence stopping particles at weak sink well cells will result in errors in individual pathline traces, particle travel times, and capture zone delineation. The most direct method to avoid these errors is to employ a weak sink cell rediscretization scheme as proposed by Spitz et al. (2001) and Paschke et al. (2007) or to use an analytical solution inside the weak sink cell (Zheng 1994). However, in general, the CRFD for the well catchment and the watershed in which it resides, comes out correctly. That the CRFD is so robust in MODFLOW-MODPATH modeling, especially for high capacity wells, is beneficial for the purpose of obtaining transit time distributions and related non-point source response functions, such as nitrate concentrations in those wells (Lerner and Papatolios 1993; 
Kauffman et al. 2001; Bohlke et al. 2002; McGuire and McDonnell 2005).

The modeling issues for weak sinks in MODPATH also apply to weak sources that are encountered during backtracking. Physical weak sources (a losing stream, an injection well that does not inject over the entire depth of the aquifer) and weak source cells may both occur in MODPATH. The settings proposed in this study, "always STOP" with IFACE set to 6 or "always STOP" with IFACE set to 0 , also apply to weak source surface water cells and weak source well cells, respectively.

\section{Supporting Information}

Additional Supporting Information may be found in the online version of this article and at http://www. dbabrams.com/supp/SM2012b:

Figure S1. Conceptual model of a physical weak sink (cross-section), which draws water from the upper portion of the aquifer only, and a physical strong sink, which draws water from the entire aquifer depth. We refer to this type of weak sink as a bypass weak sink.

Figure S2. Plan view image showing both underflow and bypass weak sinks.

Figure S3. Cumulative relative frequency distributions of groundwater transit times for a high capacity pumping well of rate $Q=7800 \mathrm{~m}^{3} / \mathrm{d}$ in the Maurice watershed when nearby residential wells are both included and omitted from the model. The blue arrow represents the direction of flow.

Please note: Wiley-Blackwell is not responsible for the content or functionality of any supporting information supplied by the authors. Any queries (other than missing material) should be directed to the corresponding author for the article.

\section{References}

Barlow, P.M. 1997. Particle-tracking analysis of contributing areas of public supply wells in simple and complex flow systems, Cape Cod, Massachusetts: U.S. Geological Survey Water Supply Paper 2434. Technical Report, United States Geological Survey.

Bear, J. 1972. Dynamics of Fluids in Porous Media. New York: American Elsevier Pub. Co.

Bohlke, J.K., R. Wanty, M. Tuttle, G. Delin, and M. Landon. 2002. Denitrification in the recharge area and discharge area of a transient agricultural nitrate plume in a glacial outwash sand aquifer, Minnesota. Water Resources Research 38, no. 7: 1105-1130.

Cherry, G.S. 2006. Simulation and particle-tracking analysis of ground-water flow near the Savannah River Site, Georgia and South Carolina, 2002, and for selected groundwater flow management scenarios, 2002 and 2020: U.S. Geological Survey Scientific Investigations Report 20065195. Technical Report, United States Geological Survey.

Gelhar, L.W., and J.L. Wilson. 1974. Ground-water quality modeling. Ground Water 12, no. 6: 399-408.

Haitjema, H.M. 1995. On the residence time distribution in idealized groundwatersheds. Journal of Hydrology 172: 1-4.

Kauffman, L.J., A.L. Baehr, M.A. Ayers, and P.E. Stackelberg. 2001. Effects of land use and travel time on the distribution of nitrate in the Kirkwood-Cohansey aquifer system in southern New Jersey. Water-Resources Investigations Report 01-4117. U.S. Geological Survey National WaterQuality Assessment Program. Technical report, United States Geological Survey.

Kelly, B.P. 2004. Simulation of ground-water flow, contributing recharge areas, and ground-water travel time in the Missouri River Alluvial Aquifer near Ft. Leavenworth, Kansas, Scientific Investigations Report 2004-5215. Technical report, United States Geological Survey.

Kirkham, D. 1967. Explanation of paradoxes in DupuitForchheimer seepage theory. Water Resources Research 3: 609-622.

Lerner, D.N., and K.T. Papatolios. 1993. A simple analytical approach for predicting nitrate concentrations in pumped ground water. Ground Water, 31, no. 3: 370-375.

Luther, K.H., and H.M. Haitjema. 1998. Numerical experiments on the residence time distributions of heterogeneous groundwatersheds. Journal of Hydrology 207, no 1: 1-17.

Maloszewski, P., and A. Zuber 1982. Determining the turnover time of groundwater systems with the aid of environmental tracers: 1. Models and their applicability. Journal of Hydrology 57: 207-231.

McDonald, M.G., and A.W. Harbaugh. 1988. A modular threedimensional finite difference ground-water flow model. Techniques of Water Resources Investigations Book 6 . Technical Report, United States Geological Survey.

McDonnell, J.J., K. McGuire, P. Aggarwal, K.J. Beven, D. Biondi, G. Destouni, S. Dunn, A. James, J. Kirchner, P. Kraft, S. Lyon, P. Maloszewski, B. Newman, L. Pfister, A. Rinaldo, A. Rodhe, T. Sayama, J. Seibert, K. Solomon, C. Soulsby, M. Stewart, D. Tetzlaff,C. Tobin, P. Troch, M. Weiler, A. Western, A. Worman, and S. Wrede. 2010. How old is streamwater? Open questions in catchment transit time conceptualization, modelling and analysis. Hydrological Processes 24: 1745-1754.

McGuire, K.J., and J.J. McDonnell. 2005. A review and evaluation of catchment transit time modeling. Journal of Hydrology 330, no. 3-4: 543-563.

Paschke, S.S., L.J. Kauffman, S.M. Eberts, and S.R. Hinkle. 2007. Overview of regional studies of the transport of anthropogenic and natural contaminants to public supply wells. In Hydrogeologic settings and groundwater flow simulations for regional studies of the transport of anthropogenic and natural contaminants to public supply wells- studies begun in 2001: U.S. Geological Survey Professional Paper 1737A, ed. S.S. Paschke, Technical Report, United States Geological Survey.

Pollock, D.W. 1994. User's guide for MODPATH/MODPATHPLOT, version 3: A particle tracking post-processing package for MODFLOW, the U.S. Geological Survey finite-difference ground-water flow model: U.S. Geological Survey Open-File Report 94-464, 6 ch. Technical Report, United States Geological Survey.

Rodhe, A., L. Nyberg, and K. Bishop. 1996. Transit times for water in a small till catchment from a step shift in the oxygen-18 content of the water input. Water Resources Research 32, no. 12: 3497-3511.

Spitz, F.J., R.S. Nicholson, and D.A. Pope. 2001. A nested rediscretization method to improve pathline resolution by eliminating weak sinks representing wells. Ground Water 39, no. 5: 778-785.

Visser, A., R. Heerdink, H.P. Broers, and M.F.P. Bierkens. 2009. Travel time distributions derived from particle tracking in models containing weak sinks. Ground Water 47, no. 2: 237-245.

Zheng, C. 1994. Analysis of particle tracking errors associated with spatial discretization. Ground Water 32, no. 5: $821-828$ 